\title{
Spacers made from sealed cold-drink bottles were as effective as conventional spacers in children with acute asthma
}

Zar HJ, Brown G, Donson H, et al. Home-made spacers for bronchodilator therapy in children with acute asthma: a randomised trial. Lancet 1999 Sep 18;354:979-82.

QUESTION: In children with acute asthma, are homemade spacers as effective as conventional ones for improving response to a $\beta_{2}$ agonist given by metered dose inhaler?

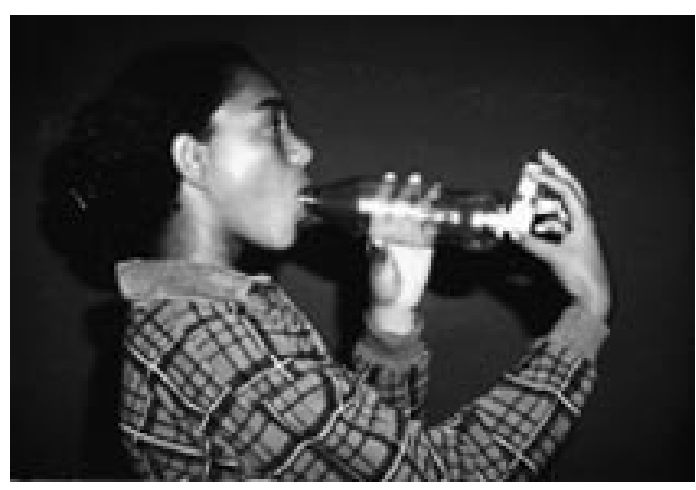

\section{Design}

Randomised \{allocation concealed*\}†, blinded (outcome assessors),* controlled trial with 15 to 30 minute follow up.

\section{Setting}

A children's hospital in South Africa.

\section{Patients}

88 children, 5 to 13 years of age (mean age $10 \mathrm{y}, 60 \%$ boys, $50 \%$ moderate to severe airway obstruction [peak expiratory flow rate $\{\mathrm{PEFR}\} 20 \%$ to $59 \%$ of predicted normal value]), with a history of asthma, and presented with an acute asthma attack. Exclusion criteria were inability to use a metered dose inhaler (MDI) and spacer or to have pulmonary function tests with PEFR $<20 \%$ of the predicted normal value, arterial $0_{2}<92 \%$ in air, or cardiac or other chronic pulmonary disease; recent use of oral corticosteroids; or use of $\beta_{2}$ agonists within 4 hours of presentation. Follow up was $100 \%$.

\section{Intervention}

Children were allocated to 1 of 4 types of spacers: a conventional spacer (Aerochamber, Trudell Medical, Canada) $(\mathrm{n}=22) ; \mathrm{a} 500 \mathrm{ml}$ plastic cold drink bottle with glue to seal the joint between the MDI and bottle $(n=22)$; an unsealed, $500 \mathrm{ml}$ plastic cold drink bottle $(\mathrm{n}=22)$; and a $200 \mathrm{ml}$ polystyrene cup $(\mathrm{n}=22)$ (figure 1). Children received fenoterol hydrobromide, $100 \mu \mathrm{g} / \mathrm{puff}$, in an MDI and spacer, 1 puff every 10 seconds. Children who weighed $\leqslant 25 \mathrm{~kg}$ received $400 \mu \mathrm{g}$; those who weighed $>25 \mathrm{~kg}$ received $600 \mu \mathrm{g}$.

\section{Main outcome measures}

Changes in clinical score and pulmonary function and need for nebulisation.

\section{Main results}

Analysis was by intention to treat. An improvement in lung function was seen in all groups. Results for the sealed bottle group were similar to those for the conventional spacer group; a cup was least effective $(\mathrm{p}=0.02)$ (table). Among children with mild-airway obstruction, clinical scores, pulmonary function, and need for nebulisation did not differ among study groups.

Among children with moderate to severe airway obstruction, clinical scores did not differ among study groups and a cup was least effective for improving pulmonary function $(\mathrm{p}<0.05)$ (table). Nebulisation was needed by 10 of 11 children who used a cup, 8 of 11 children who used a sealed bottle, 9 of 11 who used an unsealed bottle, and 4 of 11 who used a conventional spacer.

\section{Conclusion}

In children with acute asthma, spacers made from sealed cold drink bottles were as effective as conventional spacers.

*See glossary.

$\dagger$ Information supplied by author.
Source of funding: Medical Research Council of South Africa.

For correspondence. Dr H Zar, Child Health Unit, 46 Sawkins Road, Rondebosch, South Africa 7700. Fax +2727216895403.

\section{COMMENTARY}

The study by Zar and colleagues was a well designed, randomised, controlled trial-the gold standard for evaluating therapeutic methods. It shows that adequate medication delivery for asthma can be achieved with both expensive and inexpensive tools. The study took place at the Red Cross Children's Hospital in Cape Town, South Africa.

Overall, the results have practical implications for asthma guidelines in developing and industrialised countries. Some programmes only allow replacement of spacers once every 2 years. Spacers may also be the only alternative for delivery of non-nebulised anti-inflammatory medications. Furthermore, spacers can become plugged, torn, broken, or misplaced or can be left at home.

Future studies need to evaluate the use of these devices in younger children, especially in areas where neither spacers nor nebulisers are readily available. ${ }^{1}$ This study shows that homemade spacers work in the hospital setting, but will they also work in the home setting? Will differences in priming and washing alter drug delivery?

Lynnette J Mazur, MD, MPH University of Texas Houston Health Science Center

Houston, Texas, USA

1 Pedersen S, Mortensen S. Use of different inhalation devices in children. Lung 1990;168 Suppl:653-7.

Median increase in lung function at 15 to 30 minutes after an acute asthma attack for homemade spacers $v$ conventional spacers in children $\ddagger$

\begin{tabular}{|c|c|c|c|c|c|}
\hline Disease severity & Outcomes & $\begin{array}{l}\text { Conventional spacer } \\
(95 \% \mathrm{CI})\end{array}$ & $\begin{array}{l}\text { Sealed bottle } \\
\text { (Cl) }\end{array}$ & $\begin{array}{l}\text { Unsealed bottle } \\
\text { (CI) }\end{array}$ & $\begin{array}{l}\text { Cup } \\
\text { (Cl) }\end{array}$ \\
\hline \multirow[t]{2}{*}{ All children } & $\mathrm{FEV}_{1}$ & $24 \%(14$ to 37$)$ & $20 \%(15$ to 33$)$ & $17 \%(10$ to 34$)$ & $13 \%$ (0 to 23$)$ \\
\hline & FVC & $13 \%$ (6 to 20$)$ & $13 \%$ (8 to 26 ) & $10 \%$ (4 to 23$)$ & $5 \%$ (0 to 8$)$ \\
\hline \multirow{3}{*}{$\begin{array}{l}\text { Mild to moderate } \\
\text { obstruction }\end{array}$} & $\mathrm{FEV}_{1}$ & $37 \%$ (19 to 53$)$ & $33 \%(18$ to 55$)$ & $18 \%$ (9 to 57$)$ & $0 \%(-4$ to 24$) \S$ \\
\hline & PEFR & $59 \%$ (22 to 69$)$ & $36 \%$ (21 to 102$)$ & $21 \%$ (16 to 99 ) & $12 \%(-5$ to 37$) \S$ \\
\hline & FVC & $17 \%$ (8 to 22$)$ & $23 \%$ (14 to 36$)$ & $18 \%$ (5 to 26$)$ & $6 \%(-5$ to 15$) \S$ \\
\hline
\end{tabular}

$\neq F V C=$ forced vital capacity; $P E F R=$ peak expiratory flow rate. $\$$ Not significant. 